\title{
The Role of Intuition in the Creative Process of Expert Chefs
}

\begin{abstract}
Scholars studying intuition are frequently focusing on decision-takers and to this day conceptualize intuition as a form of judgment. More recently, the notion of intuition in creativity has been challenged by the argument that although the creative process may contain intuitive judgments, any creative idea or solution is essentially the result of intuitive insight. This interpretivist study seeks an increased understanding of the role of intuition in the creative process by providing empirical evidence from in-depth interviews with expert chefs. The findings show that the interviewees describe their experiences of the creative process in line with how the literature describes intuition and explain intuitive insight and judgment as instantaneous yet distinct and rapid processes.
\end{abstract}

\section{THEORETICAL BACKGROUND}

For a long time, intuition had been associated with mystical or, at least, unscientific conceptualizations, even though a number of philosophers emphasized its significance. More recently, however, we have seen a rejuvenation of academic interest in intuition, and it has become recognized as an important topic in both psychology and management research (e.g. Akinci \& Sadler-Smith, 2012; Matzler et al., 2007; Matzler et al., 2014; Osbeck, 1999, 2001; Sadler-Smith, 2008). To date, however, it remains perhaps the least understood phenomenon of managerial cognition (Hodgkinson \& Healey, 2011), and intuition in creativity, in particular, is considered to be the least explored area of intuition research (Dörfler \& Ackermann, 2012). As the renewed interest in intuition stems from researchers interested in decision takers, it is generally defined as "affectively charged judgment that arises through rapid, non-conscious and 
holistic associations" (Dane \& Pratt, 2007: 40). Intuition is also acknowledged by managers to be a widely practiced locus of direction (Matzler et al., 2014; Mintzberg, 1976) that is usually associated with increasingly unstructured and complex problems that demand resolution under significant time constraints amid a sea of available information (Hodgkinson et al., 2009).

Despite the fact that intuition has proven to be vital in finding novel solutions quickly, contributions to the literature on the role of intuition in creativity are sparse (e.g. Claxton, 1998; Dane \& Pratt, 2009; Dörfler \& Ackermann, 2012; Hodgkinson et al., 2009; Sinclair, 2010). The little that is known so far seems to be of a more general nature, stating, for example, that high level of expertise is a necessary antecedent to trustworthy intuition (Dane \& Pratt, 2009; Dijksterhuis \& Nordgren, 2006; Kahneman \& Klein, 2009).

More recently, Dörfler and Ackermann (2012) have challenged the notion of intuition in creativity. They argue that although the creative process may contain intuitive judgments by which several decisions may be tacitly incorporated into a cognitive roadmap (e.g. deciding on the path of direction of a research project), any creative idea or solution is essentially the result of intuitive insight by which the elements of the respective domain knowledge are tacitly synthesized in a new way creating a novum. In other words, intuitive judgment can be defined as the act of tacitly integrating the factors involved in a decision into a picture about what to do and intuitive insight can be defined as the act of tacitly synthesizing the components of the domain knowledge in a novel way, thus creating knowledge that did not exist before (Dörfler \& Ackermann, 2012: 559). In the domain of haute cuisine, for example, intuitive judgment entails assessing whether an unusual flavor combination will prove to be delicious or not (taking into consideration a particular event, setting, customer), whereas intuitive insight entails creating a beautiful new flavor combination. 
The contribution of this paper is an increased understanding of the role of intuition in the creative process by providing empirical evidence from in-depth interviews with expert chefs, which were initially conducted to explore the experience of creativity and the creative process. When we were analyzing the transcripts, however, we observed what may be termed 'moments of intuition', which are frequently characterized by the cognitive linking of previously unrelated concepts (Hodgkinson et al., 2009). In this paper, we present and discuss these moments of intuition and their role in the creative process of expert chefs. Furthermore, in line with other interpretivist researchers, we appreciate that the concept of intuition in creativity is socially constructed (Crossan et al., 1999; Sinclair \& Hamilton, 2014) and acknowledge that it may sometimes "remain inexpressible in words or other symbols" (Dörfler \& Ackermann, 2012: 556), and loaded with contextual interpretations (Dörfler \& Eden, 2014; Stierand \& Dörfler, 2014).

\section{METHODS}

\section{Study Context}

We conducted our research in an important but under-researched field of the creative industries and cultural economy, haute cuisine, where creativity is a fundamental expectation by both paying customers and the domain's two leading gatekeepers (Petruzzelli \& Savino, 2014; Stierand, 2015; Stierand et al., 2014; Svejenova et al., 2007; Svejenova et al., 2010; Woodward \& Stierand, 2014): the Michelin (ratings are on a one- to three-star scale) and Gault Millau (ratings are on a 1- to 20-point scale) restaurant guides. Therefore, we have used these two guides for identifying our chef participants (see Table 1), who all signed an information release form and agreed that we could attribute quotations to them by name. 
TABLE 1. Participants

\begin{tabular}{|c|c|c|c|}
\hline Name of Chef & \multicolumn{2}{|c|}{$\begin{array}{l}\text { Michelin/Gault } \\
\text { Millau ranking } \\
\text { (at time of research) }\end{array}$} & Affiliation \\
\hline \multicolumn{4}{|l|}{$U K$} \\
\hline Fergus Henderson & $1^{*}$ & $\mathrm{n} / \mathrm{a}$ & St John's, London \\
\hline Raymond Blanc & $2 *$ & $\mathrm{n} / \mathrm{a}$ & Le Manoir aux Quat'Saisons, Great Milton \\
\hline \multicolumn{4}{|l|}{ France } \\
\hline Jean-Georges Klein & $3^{*}$ & 18 & L'Arnsbourg, Baerenthal \\
\hline Michel Troisgros & $3 *$ & 19 & Maison Troisgros, Roanne \\
\hline Michel Bras & $3^{*}$ & 19 & Bras, Laguiole \\
\hline Sébastien Bras & $3 *$ & 19 & Bras, Laguiole \\
\hline \multicolumn{4}{|l|}{ Spain } \\
\hline Andoni Luis Aduriz & $2^{*}$ & $\mathrm{n} / \mathrm{a}$ & Mugaritz, Errenteria \\
\hline Joan Roca & $2^{*}$ & $\mathrm{n} / \mathrm{a}$ & El Celler de Can Roca, Girona \\
\hline Ferran Adrià & $3^{*}$ & $\mathrm{n} / \mathrm{a}$ & El Bulli, Roses \\
\hline \multicolumn{4}{|l|}{ Austria } \\
\hline Heinz Reitbauer & $2^{*}$ & 19 & Steirereck, Vienna \\
\hline Roland Trettl & $1^{*}$ & 18 & Ikarus im Hangar-7, Salzburg \\
\hline \multicolumn{4}{|l|}{ Germany } \\
\hline Harald Wohlfahrt & $3 *$ & 19 & Schwarzwaldstube, Baiersbronn \\
\hline Dieter Müller & $3 *$ & 19 & Dieter Müller, Bergisch Gladbach \\
\hline Nils Henkel & $3^{*}$ & 19 & Gourmetrestaurant Lerbach, Bergisch Gladbach \\
\hline Heinz Winkler & $3 *$ & 19 & Venezianisches Restaurant, Aschau \\
\hline Hans Haas & $2^{*}$ & 18 & Tantris, Munich \\
\hline Joachim Wissler & $3 *$ & 19 & Vendôme, Bergisch Gladbach \\
\hline Juan Amador & $3^{*}$ & 17 & Amador, Langen \\
\hline
\end{tabular}

\section{Participants and Data Collection}

Due to the high complexity and limited academic understanding of the research topic, we follow a qualitative research design that can capture people's experiences (Stierand \& Dörfler, 2014). Data was collected through 18 face-to-face, semi-structured, in-depth interviews with chefs from France, Spain, Austria, Germany, and the UK. In addition, we recorded observational, 
theoretical and methodological notes in a research diary prior to and after each interview as well as during and after restaurant tours and invited lunches. These notes were explanatory in nature and helped us to recall aspects the participants revealed during the interview, but which may otherwise remain difficult to uncover in the transcripts only.

The fact that the chefs are mentioned in the aforementioned restaurant guides further guarantees that they had significant and repeated experience of the creative process and therefore can be regarded as 'knowledgeable agents' who have clear goals and are able to report and "explain their thoughts, actions and intentions" (Gioia et al., 2013: 17). Thus, a non-probability, purposeful sampling strategy was employed, making use of snowballing and a personal industry contact of the lead researcher, who had been a chef in haute cuisine. The lead researcher's status as a 'native' (Brannick \& Coghlan, 2007) led to increased insight (Fisher \& Hutchings, 2013), because it facilitated trust-building and enabled deeper conversations between professionals, which would have been more difficult to achieve otherwise (see Gioia \& Chittipeddi, 1991). The advantage of the lead researcher's status as a 'native' was particularly apparent when interviewees used specialist terms of the profession and examples from practice.

\section{Data Analysis}

However, the status as a 'native' demanded rigorous self-reflection which was supported by critical discussions within the research team after each interview in order to stay alert to any influences that might have blurred the understanding of the interviewees' accounts. Thus, the process of bracketing was used whereby "one looks at the data with the attitude of relative openness" (Giorgi, 1994: 212). This process can be seen as a "dialectic movement between bracketing preunderstandings and exploiting them reflexively as a source of insight" (Finlay, 2009: 13). In practice, this meant that the lead researcher discussed the data collection 
experiences and data interpretations with the second-named author. We believe that this reflective exchange facilitated a more consistent interpretation process and trustworthy findings, because it aided the identification of influences that might have biased or blurred the interpretation.

All interviews were recorded, fully transcribed, and the meaning units of those interviews not conducted in English were translated in order to allow all members of the research team to read and understand the data . The transcripts were first analyzed using Giorgi's (1994) descriptive phenomenological method, which was followed by a second and interpretiveexplanatory level of analysis. The thematic structure of the analyzed data can be seen in Figure 1.

FIGURE 1. Thematic structure of analyzed data

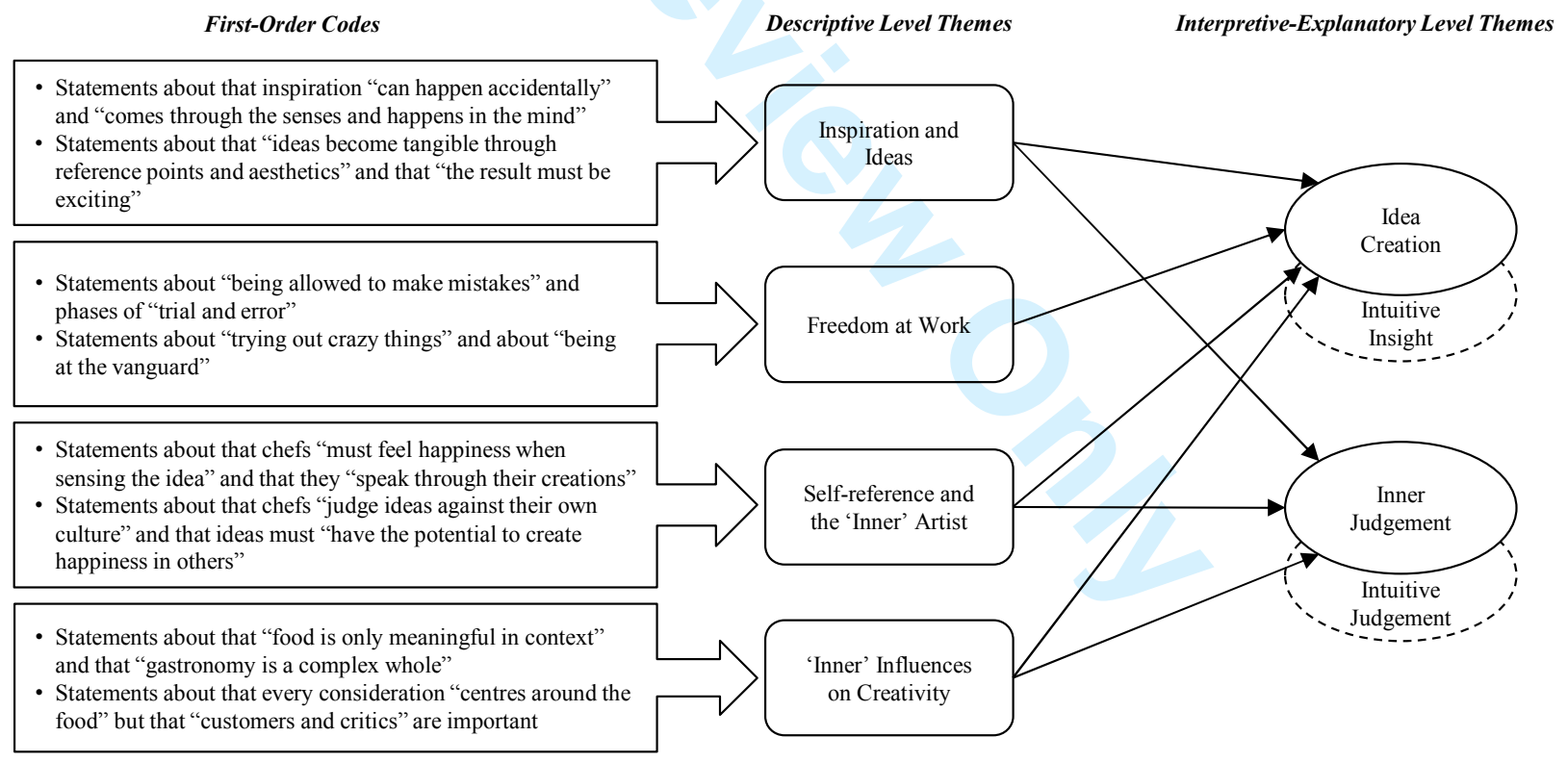

\section{FINDINGS AND DISCUSSION}

A widely held belief states that creativity shares many cognitive processes with problemsolving (Mumford et al., 1991; Reiter-Palmon \& Illies, 2004) even though the relationship between the two is subject to a vigorous debate between those who argue that creativity is a 
special form of problem-solving and those who defend the opposite. The majority of authors, however, advocate that the core processes inherent in both creativity and problem-solving can be categorized into an idea generation phase (which encloses our theme of 'idea creation') and an idea evaluation phase (which encloses our theme of 'inner judgment') (Basadur, 1997; Finke et al., 1992; Mumford, 2001; Mumford \& Connelly, 1992; Reiter-Palmon \& Illies, 2004). Hence, with some simplification, we could say that intuitive insight can be placed in the idea generation phase and intuitive judgment in the idea evaluation phase.

The chefs mentioned that their ideas often appear while they are engaged in ordinary everyday activities, such as going for a run, watching a movie, deboning a saddle of lamb and smelling spices and herbs, or just by touching beautiful produce.

Great chefs... are so much in love with their food, they are able to touch their food and almost do things intuitively. (Raymond Blanc)

Harald Wohlfahrt referred to the process of idea generation as a kind of daydreaming during which different ingredients furtively appear, which he then cognitively combines. This is a description that was also confirmed by Nils Henkel and Dieter Müller who called it an intellectual and imaginative play with the sensory system to create new textures and flavours. Michel Trosigros said that creating ideas requires thinking and feeling.

However, we can only assume that these examples of idea generation contain intuitive insight, even though the wording the chefs used is a strong indication. More obvious examples are those that seem to have happened accidentally. Dieter Müller, for instance, mentioned that he once entered the cold store in his restaurant and got annoyed, because one of his chefs had left the crayfish next to the sweetbreads. 
It made click in my head. Let's do sweetbreads with crayfish. That's how it starts and then it goes back and forth. (Dieter Müller)

Dieter Müller's intuitive insight resulted in a famous dish named Cassoulet von Bach und Wiese (engl. Cassoulet of River and Field) that became widely recognized for its creativity. Yet, for these creative intuitive incidents to happen, the mind has to be free and the workplace has to allow failures, said Harald Wohlfahrt, because creativity cannot be forced. Andoni Luis Aduriz phrased it in a similar vein:

You have to be an innovator in an obsessive way. I am not going to say 'I want to be an innovator'. Crazy! I am going to color my hair red and wear latex. So, innovation has to give me the process; it is a way of doing things. (Andoni Luis Aduriz)

Our findings do not suggest that intuitive insight is more likely to be found in moments of serendipitous idea generation. These moments just seem to happen to be the obvious ground where intuitive insight is sparked, because more deliberate and systematic approaches to idea generation often employ more analytical and therefore non-intuitive activities. For example, Michel Troisgros explained that he deliberately and systematically plays with shadow and light like a painter, but with the aim to create unexpected experiences that invite him to discover hidden flavours.

My cuisine is very particular; special...like a personal signature of acidity. I work a lot on the relations of acidity...like a play of contrasts, a play between shadow and light. (Michel Troisgros)

Hence, it is reasonable to assume that the idea generation phase is predominantly intrapersonal. Joan Roca, for example, mentioned that he and his brothers always evaluate ideas on the basis of their personal manifesto, a kind of culinary value system that harmoniously unites 
wine, smell, balance of flavours, and tradition. Our findings further suggest that the idea evaluation phase of expert chefs consists of both intra-personal judgment and what we call intrapersonal interpretation of inter-personal judgment. The latter may include, for example, intrapersonal interpretation of how critics of restaurants guides may judge a specific dish or cuisine. The art of cooking is in simplicity, but...sometimes I think back to my childhood, going for a walk, seeing fruits or veg and so on,...one could do a great cuisine there, but, unfortunately, this will not be recognised enough, because the media will not report about it...like about a chef who cooks a crazy cuisine with little things here and a drop of sauce there. (Dieter Müller)

Hence, we believe that the role of intuition in the creative process of expert chefs is to create rapid feedback and feedforward loops between idea generation and idea evaluation. This was expressed very poetically by Raymond Blanc:

You work for the sake of beauty...to touch excellence; even if it is for seconds; between seconds...you want to go to the heart... when you do a dish, or you create a new environment, or a new breakfast...it is for it! And then the by-product of that, of course, is that it will make you so much happier! And then there is the element of the guest, but it is for it first. (Raymond Blanc)

Since we were not asking the chefs interviewed specifically about intuition, but about their experience of the creative process, not all chefs explicitly used the term intuition and none of them used intuitive insight or intuitive judgment. However, the chefs described their experiences very much in line with how the literature describes intuition and we believe that this strengthens rather than weakens our findings. The chefs' quotes clearly show that intuitive insight and judgment are instantaneous and that intuitive judgment often immediately follows intuitive 
insight, making a clear distinction between these two rapid processes very challenging from a research perspective.

\section{DISCUSSION AND CONCLUSION}

As the findings of our study show, the phenomenon of intuition may continue to be difficult to express in clear-cut terms (Dörfler \& Ackermann, 2012), because it is fundamentally a 'direct knowing' (Behling \& Eckel, 1991; Osbeck, 2001; Sinclair, 2011), 2011), a knowing without knowing how (Vaughan, 1979). In the context of expert chefs, we may therefore describe intuition as a kind of 'sensory knowing' (see Cunliffe \& Coupland, 2012; Stierand, 2015), which seems to thrive during activities for which the chefs have learned to automatize the execution process (Sadler-Smith, 2008).

The findings also show that the conceptualisation of intuitive insight as distinct from intuitive judgment complements the intuition-as-judgment view and offers a more nuanced and comprehensive portrait of intuition (see Dörfler \& Ackermann, 2012). On the one hand, we have exposed how the two forms of intuition are intertwined and the difficulties this poses to further studies of intuition. On the other hand, we were able to interpret from the interview data that expert chefs use intuitive insight during the idea generation phase and intuitive judgment during the idea evaluation phase. The latter has been argued to consist of both intra-personal judgment and, what we call, intra-personal interpretation of inter-personal judgment.

Intra-personal judgment is a result of an individual's intrinsic motivation to create (Baker-Sennett \& Ceci, 1996; Eisenberger et al., 1999; Getzels, 1975; Koestler, 1964; Ryan \& Deci, 1985; Simonton, 1988) and entails both conscious and analytical phases as well as nonconscious and intuitive phases (Dane \& Pratt, 2007; Dörfler \& Ackermann, 2012). The intrapersonal interpretation of inter-personal judgment, in contrast, stems from intuitively evaluating 
the inherited occupational practices and socio-cultural conventions of the domain (Csíkszentmihályi, 2014; Hardy et al., 2005; Kogut \& Zander, 1996; Philips et al., 2004; Tsoukas, 2009; Tsoukas \& Vladimirou, 2001), which act as an omnipresent but tacit sensemaking foundation (Dreyfus, 1991; Tsoukas, 2005, 2009) from which intuitive insights originate (Crossan et al., 1999).

We hope to have demonstrated that qualitative-interpretivist studies, in general, and those employing a 'native', in particular, are valuable for unravelling some of the salient features of intuition and creativity (Stierand \& Dörfler, 2014) that are embodied and atheoretical (Chia, 2003), and, otherwise would remain largely 'unspoken and unspeakable' (Stierand, 2015). Our plan is to extend our research into several other directions. First, we plan to conduct more interviews with expert chefs to bolster our findings; we are particularly interested in interviewing chefs outside Europe. Second, we plan to extend our inquiry into other domains such as science, art, and creative teams in organizations. Therefore our findings should be regarded as provisional.

\section{REFERENCES}

Akinci, C. \& Sadler-Smith, E. (2012) 'Intuition in Management Research: A Historical Review', International Journal of Management Reviews, 14(1): 104-122.

Baker-Sennett, J. \& Ceci, S. J. (1996) 'Clue-Efficiency and Insight: Unveiling the Mystery of Inductive Leaps', Journal of Creative Behavior, 30(3): 153-172.

Basadur, M. (1997) 'Organizational Development Interventions for Enhancing Creativity in the Workplace', Journal of Creative Behavior, 31(1): 59-72.

Behling, O. \& Eckel, N. (1991) 'Making Sense out of Intuition', The Academy of Management Executive, 5(1): 46-54. 
Brannick, T. \& Coghlan, D. (2007) 'In Defense of Being "Native": The Case for Insider Academic Research', Organizational Research Methods, 10(1): 59-74.

Chia, R. (2003) 'From Knowledge-Creation to the Perfecting of Action: Tao, Basho and Pure Experience as the Ultimate Ground of Knowing', Human Relations, 56(8): 953-981.

Claxton, G. (1998) 'Investigating Human Intuition: Knowing without Knowing Why', The Psychologist 11(5): 217-220.

Crossan, M., Lane, H. \& White, R. (1999) 'An Organizational Learning Framework: From Intuition to Institution', Academy of Management Review, 24(3): 522-537.

Csíkszentmihályi, M. (Ed.) (2014) The Systems Model of Creativity: The Collected Works of Mihaly Csikszentmihalyi, Springer, Dordrecht.

Cunliffe, A. \& Coupland, C. (2012) 'From Hero to Villain to Hero: Making Experience Sensible through Embodied Narrative Sensemaking', Human Relations, 65(1): 63-88.

Dane, E. \& Pratt, M. (2007) 'Exploring Intuition and Its Role in Managerial Decision Making', Academy of Management Review, 32(1): 33-54.

Dane, E. \& Pratt, M. (2009) 'Conceptualizing and Measuring Intuition: A Review of Recent Trends', in G. Hodgkinson \& J. Ford (eds) International Review of Industrial and Organizational Psychology, pp. 1-40. Chichester: Wiley.

Dijksterhuis, A. \& Nordgren, L. (2006) 'A Theory of Unconscious Thought', Perspectives on Psychological Science, 1(2): 95-109.

Dörfler, V. \& Ackermann, F. (2012) 'Understanding Intuition: The Case for Two Forms of Intuition', Management Learning, 43(5): 545-564.

Dörfler, V. \& Eden, C. (2014) 'Research on Intuition Using Intuition', in M. Sinclair (ed) Handbook of Research Methods on Intuition, pp. 264-276. Cheltenham: Edward Elgar. 
Dreyfus, H. (1991) Being-in-the-World. Cambridge, MA: MIT Press.

Eisenberger, R., Pierce, D. \& Cameron, J. (1999) 'Effects of Reward on Intrinsic MotivationNegative, Neutral, and Positive: Comment on Deci, Koestner, and Ryan (1999)', Psychological Bulletin, 125(6): 677-691.

Finke, R., Ward, T. \& Smith, S. (1992) Creative Cognition: Theory, Research, and Applications. Cambridge, MA: MIT Press.

Finlay, L. (2009) 'Debating Phenomenological Research Methods', Phenomenology \& Practice, 3: 6-25.

Fisher, K. \& Hutchings, K. (2013) 'Making Sense of Cultural Distance for Military Expatriates Operating in an Extreme Context', Journal of Organizational Behavior, 34(6): 791-812.

Getzels, J. (1975) 'Creativity: Prospects and Issues', in I. Taylor \& J. Getzels (eds) Perspectives in Creativity, pp. 326-344. Aldine: Chicago.

Gioia, D. \& Chittipeddi, K. (1991) 'Sensemaking and Sensegiving in Strategic Change Initiation', Strategic Management Journal, 12(6): 433-448.

Gioia, D., Corley, K. \& Hamilton, A. (2013) 'Seeking Qualitative Rigor in Inductive Research: Notes on the Gioia Methodology', Organizational Research Methods, 16(1): 15-31.

Giorgi, A. (1994) 'A Phenomenological Perspective on Certain Qualitative Research Methods', Journal of Phenomenological Psychology, 25(2): 190-220.

Hardy, C., Lawrence, T. \& Grant, D. (2005) 'Discourse and Collaboration: The Role of Conversations and Collective Identity', Academy of Management Review, 30(1): 58-77.

Hodgkinson, G. \& Healey, M. (2011) 'Psychological Foundations of Dynamic Capabilities: Reflexion and Reflection in Strategic Management', Strategic Management Journal, 32(13): 1500-1516. 
Hodgkinson, G., Sadler-Smith, E., Burke, L., Claxton, G. \& Sparrow, P. (2009) 'Intuition in Organizations: Implications for Strategic Management', Long Range Planning, 4: $277-$ 297.

Kahneman, D. \& Klein, G. (2009) 'Conditions for Intuitive Expertise: A Failure to Disagree', American Psychologist, 64(6): 515-526.

Koestler, A. (1964) The Act of Creation. New York: Penguin.

Kogut, B. \& Zander, U. (1996) 'What Firms Do? Coordination, Identity, and Learning', Organization Science, 7(5): 502-518.

Matzler, K., Bailom, F. \& Mooradian, T. (2007) 'Intuitive Decision Making', Sloan Management Review, 49(1): 13-15.

Matzler, K., Uzelac, B. \& Bauer, F. (2014) 'The Role of Intuition and Deliberation for Exploration and Exploitation Success', Creativity and Innovation Management, 23(3): 252-263.

Mintzberg, H. (1976) 'Planning on the Left Side and Managing on the Right.', Harvard Business Review, 54(4): 49-58.

Mumford, M. (2001) 'Something Old, Something New: Revisiting Guilford's Conception of Creative Problem Solving', Creativity Research Journal, 13(3-4): 267-276.

Mumford, M. \& Connelly, M. (1992) 'Leaders as Creators: Leader Performance and Problem Solving in Ill-Defined Domains', The Leadership Quarterly, 2(4): 289-315.

Mumford, M., Mobley, M., Reiter-Palmon, R., Uhlman, C. \& Doares, L. (1991) 'Process Analytic Models of Creative Capacities', Creativity Research Journal, 4(2): 91-122.

Osbeck, L. (1999) 'Conceptual Problems in the Development of a Psychological Notion of 'Intuition', Journal for the Theory of Social Behaviour, 29(3): 229-249. 
Osbeck, L. (2001) 'Direct Apprehension and Social Construction: Revisiting the Concept of Intuition', Journal of Theoretical and Philosophical Psychology, 21(2): 118-131.

Petruzzelli, A. \& Savino, T. (2014) 'Search, Recombination, and Innovation: Lessons from Haute Cuisine', Long Range Planning, 47(4): 224-238.

Philips, N., Lawrence, T. \& Hardy, C. (2004) 'Discourse and Institutions', Academy of Management Review, 29(4): 635-652.

Reiter-Palmon, R. \& Illies, J. (2004) 'Leadership and Creativity: Understanding Leadership from a Creative Problem-Solving Perspective', The Leadership Quarterly, 15(1): 55-77.

Ryan, R. \& Deci, E. (1985) Intrinsic Motivation and Self-Determination in Human Behavior. New York, NY: Plenum.

Sadler-Smith, E. (2008) Inside Intuition. London, UK: Routledge.

Simonton, D. (1988) Scientific Genius: A Psychology of Science. New York, NY: Cambridge University Press.

Sinclair, M. (2010) 'Misconceptions About Intuition', Psychological Inquiry: An International Journal for the Advancement of Psychological Theory, 21(4): 378-386.

Sinclair, M. (2011) 'An Integrated Framework of Intuition', in M. Sinclair (ed) Handbook of Intuition Research, pp. 3-16. Cheltenham, UK: Edward Elgar Publishing.

Sinclair, M. \& Hamilton, A. (2014) 'Mapping Group Intuitions', in M. Sinclair (ed) Handbook of Research Methods on Intuition, pp. 199-216. Cheltenham: Edward Elgar.

Stierand, M. (2015) 'Developing Creativity in Practice: Explorations with World-Renowned Chefs', Management Learning: OnlineFirst. 
Stierand, M. \& Dörfler, V. (2014) 'Researching Intuition in Personal Creativity', in M. Sinclair (ed) Handbook of Research Methods on Intuition, pp. 249-263. Cheltenham: Edward Elgar.

Stierand, M., Dörfler, V. \& MacBryde, J. (2014) 'Creativity and Innovation in Haute Cuisine: Towards a Systemic Model', Creativity and Innovation Management, 23(1): 15-28.

Svejenova, S., Mazza, C. \& Planellas, M. (2007) 'Cooking up Change in Haute Cuisine: Ferran Adrià as an Institutional Entrepreneur', Journal of Organizational Behavior, 28(5): 539561.

Svejenova, S., Planellas, M. \& Vives, L. (2010) 'An Individual Business Model in the Making: A Chef's Quest for Creative Freedom', Long Range Planning, 43(2-3): 408-430.

Tsoukas, H. (2005) 'Do We Really Understand Tacit Knowledge?', in M. Easterby-Smith \& M. Lyles (eds) Handbook of Organizational Learning and Knowledge, pp. 410-427. Oxford: Blackwell.

Tsoukas, H. (2009) 'A Dialogical Approach to the Creation of New Knowledge in Organizations', Organization Science, 20(6): 941-957.

Tsoukas, H. \& Vladimirou, E. (2001) 'What Is Organizational Knowledge?', Journal of Management Studies, 38(7): 973-993.

Vaughan, F. (1979) Awakening Intuition. New York: Anchor Books.

Woodward, K. \& Stierand, M. (2014) 'Stars War': Conflicts between Chefs and Restaurant Guides', in I. Pantelidis (ed) The Routledge Handbook of Hospitality Management, pp. 227-236. London: Sage. 
Dear Dr Sowden,

We are very excited to have been given the opportunity to revise our manuscript (ID: JOCB02-15-0320) entitled "The Role of Intuition in the Creative Process of Expert Chefs" for The Journal of Creative Behavior. We carefully considered your comments as well as those offered by the two reviewers. Herein, we explain how we revised the paper based on those comments and recommendations. We would like to extend our appreciation for taking the time and effort necessary to provide such insightful guidance. The comments and guidance we have received were extremely helpful and constructive.

We believe that the revised version of our paper includes a number of positive changes and we hope that the revisions improve the paper such that you and the reviewers now deem it worthy of publication in The Journal of Creative Behavior. Unfortunately, the response to the reviewers' comments involved making the article slightly longer than the original submission, a problem we will immediately attend to once the reviewers agree with the direction of our changes. We will do our utmost not to exceed 4,250 words. Next, we offer a detailed response to the reviewers' comments.

\section{Response to reviewer 1:}

1. This submission carries much potential for producing a fascinating article. However it needs to be clarified and expanded in order to offer a clear and credible analysis. The paper consists of circa 4250 words which is far short of the journal's word limit of 8000 words. This is rather puzzling because the problems that I have identified are due to a lack of relevant material having been presented. I would invite the authors to extend their paper.

- Thank you for the kind words and encouragement. We appreciate your point about the length of the paper. However, given the strict 4,000 word limit per article for this particular special issue, it is important that any changes we make do not increase the length of the article (as emphasised by the editor in his decision letter), which already stands at 4,250 words. Thus, we hope that our efforts to restructure the paper and to provide additional interview quotes are convincing and sufficient. 
2. If the authors subscribe to the idea of intuiting as 'embodied...unspoken and unspeakable' (pp.9-10), how do they justify having participants speak about this and then treating the data as mapping onto the intuiting process? What status do the authors believe can be given to their data?

- Thank you very much for pointing out this very important point. We have now rephrased the section as follows: "We hope to have demonstrated that qualitative-interpretivist studies, in general, and those employing a 'native', in particular, are valuable for unravelling some of the salient features of intuition and creativity (Stierand \& Dörfler, 2014) that are embodied and atheoretical (Chia, 2003), and, otherwise would remain largely 'unspoken and unspeakable' (Stierand, 2015)." The apparent contradiction is thus resolved as the process of intuiting, we believe, is unspoken and unspeakable but 'intuitors' develop an understanding of this process and therefore can speak about it, i.e. they can articulate it in terms and metaphors embedded in their knowledge tradition, and therefore the it is 'accessible' to the 'native'. As we have mentioned in the last sentence of the paper, we consider our findings as provisional until they can be compared to those of other studies. However, on page 9 we argue that despite the fact that "we were not asking the chefs interviewed specifically about intuition, but about their experience of the creative process...", they "described their experiences very much in line with how the literature describes intuition and we believe that this strengthens rather than weakens our findings." As you mention in your review (see 8.), we "present some fascinating observations but it is not always clear where these have come from because so little data have been presented." We believe that we have now been more explicit about how we have grounded the analysis in the relevant data.

3. The methodological account is brief and vague. It does not make explicit the method of analysis that was used. The authors cite original grounded theory work (Glaser and Strauss, 1967) (which is rarely used nowadays: grounded theorists tend go down the Strauss and Corbin route or the Charmaz route) and Miles and Huberman's (1994) type of thematic analysis but they never name what they have done. The reference to 'constant comparison techniques' again suggests grounded theory but the authors do not seem to have had theory generation as their aim so there is no justification for using that 
method. So the question is what exactly did they do on a step-by-step basis and which qualitative method was this?

- We are extremely thankful for this comment and have rewritten the entire methods section in an attempt to be more explicit about the methods we have employed. Your point about grounded theory is valid and we acknowledge that the initial methods section could suggest that we have followed grounded theory. However, we did not follow any variant of grounded theory and cited Glaser and Strauss' classic work only, because they describe the notions of 'constant comparison techniques' and 'the iterative nature of coding', and are widely cited in other qualitative-interpretivist studies that also do not use grounded theory. We feel much more comfortable with the current description of the methods section and, once again, want to thank you for your constructive and thoughtful comments.

4. The paper states that interviews 'not conducted in English were translated in order to allow all members of the research team to read and understand the data'. In this situation, the standard, expected practice is for some back-translation to be undertaken to provide a measure of translation accuracy. Was this undertaken for these data? If so, what was the outcome? If not, why not?

- We are happy to provide you with further explanation as to why we have not conducted back-translation. Some of the interviews were conducted in French and were later translated by a very close family member who is a native French speaker and fluent in English. Other interviews were conducted in German and later translated into English by the lead researcher, who is German and speaks English fluently. Two interviews were conducted in Spanish together with a native English speaker who is fluent in Spanish and who translated the interview live for the lead researcher; in this case clarification questions were asked by the lead researcher thus the same a similar degree of clarity was achieved as is intended by applying backtranslation. When the lead researcher did the translation this was achieved directly, while in the case of the French interviews there were conversations between the lead researcher and the translator clarifying any ambiguous points. In addition, we were focusing on a process of translating 'meaning units' to capture their gist rather than verbatim translation. Translating to 
capture the gist does not necessarily lend itself to a simple back-translation since the latter assumes vocabulary equivalence, which, as we know from practice, does not always work. The French concept of "terroir", for example, has no direct equivalents in the English language. We hope that this is a satisfactory explanation and we would be happy to provide you with more information on this process if necessary.

5. What do the authors mean when they say they used 'intercoder agreement' to validate their analysis? What did this involve and what were its outcomes?

- We are very thankful for this comment, because we realised that the term 'intercoder agreement' is often used differently in the literature from how we have understood it and this was clearly our oversight. This means that we have not calculated the agreement as percentage figure, but went through a process of reflective discussions among the research team members in order to establish a consensus on the meaning units and how they form themes and ultimately a convincing story of the interviewees' accounts. We have therefore decided to delete the term 'intercoder agreement' in the manuscript and replaced it with the following statement in the methods section: "The advantage of the lead researcher's status as a 'native' was particularly apparent when interviewees used specialist terms of the profession and examples from practice, because the lead researcher was able to understand and make immediately sense of these terms and examples.... However, the status as a 'native' demanded rigorous self-reflection which was supported by critical discussions within the research team after each interview in order to stay alert to any influences that might have blurred the understanding of the interviewees' accounts. Thus, the process of bracketing was used whereby "one looks at the data with the attitude of relative openness" (Giorgi, 1994: 212). This process can be seen as a "dialectic movement between bracketing preunderstandings and exploiting them reflexively as a source of insight" (Finlay, 2009: 13). In practice, this meant that the lead researcher discussed the data collection experiences and data interpretations with the secondnamed author. We believe that this reflective exchange facilitated a more consistent interpretation process and trustworthy findings, because it aided the identification of influences that might have biased or blurred the 
interpretation." We hope that we have now explained our thematic structuring and sensemaking of the data to a satisfactory level.

6. Did the participants agree that the authors could attribute quotations to them by name?

- Yes, all interviewees signed an information release form and agreed that we could attribute quotations to them by name their names. We are happy to share scans of these forms if needed.

7. The analysis is interesting but needs to be much more fully grounded in relevant data. As it stands, the authors present some fascinating observations but it is not always clear where these have come from because so little data have been presented. Grounding an analysis firmly and fully in relevant data is the sine qua non for qualitative research.

- We acknowledge your concerns and have therefore rewritten the findings and discussion sections. We now also provide additional quotes from the interviews (In addition, please see our reply to reviewer 2, 10.).

8. The analytic narrative involves a confusing combination of some data, some interpretation by the authors and a lot of invocation of relevant research. This creates a sense of the analysis having been driven by that research, despite the protestations to the contrary on p.6. I would suggest restructuring the 'Findings' section to focus on data and interpretations and then discussing the findings in relation to relevant research and theory in a discussion or conclusion section.

- Thank you very much for this constructive suggestion, which we have now fully implemented. The 'Findings' section starts, however, with a short introduction and refers to some literature that establishes the link between the notions of idea generation/idea evaluation and intuitive insight/intuitive judgment. We hope that this is acceptable.

9. What assurances can the authors provide that the analysis was not overly driven by research and theory? What steps did they take to ensure this was not the case?

- We hope that our new methods section delivers sufficient reassurance to your concerns. In addition, we are very happy, if need be, to share our interview transcripts with you as well as our thematic analysis files. 


\section{Response to reviewer 2:}

10. This is a really interesting article to read and offers some plausible and well-argued conclusions, though there were a few small points I wanted to raise. Your data seems very rich and interesting, drawing on quite an exclusive sample group, so it would be great to bring the interview data more to the fore and make more use of it in the article. For example, the paragraph on serendipitous idea generation (page 8, lines 4-13) might benefit from being illustrated with actual extracts from your interviews rather than just summarised. Similarly the discussion of intra vs inter personal processes that follows it, though currently adequate, could be really bought to life by drawing on extracts from your data.

- Thank you very much for these useful comments. We have now added a direct interview quote to the paragraph on serendipitous idea generation: "My cuisine is very particular; special...like a personal signature of acidity. I work a lot on the relations of acidity...like a play of contrasts, a play between shadow and light. (Michel Troisgros)" and one to the discussion on intra vs inter personal processes: "The art of cooking is in simplicity, but...sometimes I think back to my childhood, going for a walk, seeing fruits or veg and so on,...one could do a great cuisine there, but, unfortunately, this will not be recognised enough, because the media will not report about it...like about a chef who cooks a crazy cuisine with little things here and a drop of sauce there. (Dieter Müller)"

11. Page 2, lines 21-23 - is a little confusing as "assessing whether an unusual flavour combination is delicious or not" seems to imply you're assessing this by tasting the food rather than making an intuitive judgement about whether the potential combination would work. Maybe "will prove to be delicious" would be clearer.

- We fully agree with your comment here and have now rephrased as you suggest.

12. Page 10, line 5 - "imposes to" sounds wrong. Perhaps "poses to " or "imposes on" would work better.

- Thank you for pointing this out. We have now changed "imposes to" to "poses to". 
13. Given that your participants are evidently willing to be identified it might be worth stating briefly in the method that they have agreed to this.

- Thank you for this important comment, which was also raised by reviewer 1 . We have now included the following on $p$. 3: "Therefore, we have used these two guides for identifying our chef participants (see Table 1), who all signed an information release form and agreed that we could attribute quotations to them by name."

14. Also, could you clarify the data analysis technique you used, at the moment it reads broadly as thematic analysis but the references to Glaser and Strauss seem to suggest a grounded theory influence. There's nothing wrong with using one or the other or mixing both, but best to state overtly that you've done so, both for clarity and to help others replicate your approach.

- We are extremely thankful for this comment and have rewritten the entire methods section in an attempt to be more explicit about the methods we have employed (in addition, please see our reply to reviewer 1, 3.).

15. On the subject of thematic analysis, providing a table or brief summary of the themes themselves might usefully help bridge your "method" and "findings and discussion" sections.

- Thank you very much for this very constructive suggestion, which we have now implemented. On p. 6 you can now find FIGURE 1. Thematic structure of analyzed data. 